\title{
Longitudinal predictors of Chinese word reading and spelling among elementary grade students
}

\author{
PUI-SZE YEUNG, CONNIE SUK-HAN HO, and YAU-KAI WONG \\ University of Hong Kong
}

DAVID WAI-OCK CHAN

Chinese University of Hong Kong

KEVIN KIEN-HOA CHUNG

Hong Kong Institute of Education

LAP-YAN LO

Hong Kong Shue Yan University

Received: July 27, 2010 Accepted for publication: November 7, 2011

\begin{abstract}
ADDRESS FOR CORRESPONDENCE
Connie Suk-Han Ho, Department of Psychology, Knowles 616A, University of Hong Kong, Pokfulam Road, Hong Kong. E-mail: shhoc@hku.hk
\end{abstract}

\begin{abstract}
The longitudinal predictive power of four important reading-related skills (phonological skills, rapid naming, orthographic skills, and morphological awareness) to Chinese word reading and writing to dictation (i.e., spelling) was examined in a 3-year longitudinal study among 251 Chinese elementary students. Rapid naming, orthographic skills, and morphological awareness assessed in Grade 1 were significant longitudinal predictors of Chinese word reading in Grades 1 to 4 . As for word spelling, rapid naming was the only significant predictor across grades. Morphological awareness was a robust predictor of word spelling in Grade 1 only. Phonological skills and orthographic skills significantly predicted word spelling in Grades 2 and 4. After controlling for autoregressive effects, morphological awareness and orthographic skills were the significant longitudinal predictors of Chinese word reading and word spelling, respectively. These findings reflected the impacts of the Chinese orthography on children's reading and spelling development.
\end{abstract}

Research in the past decade has suggested that phonological skills, rapid naming, orthographic skills, and morphological awareness are important reading-related skills for learning to read and write Chinese (e.g., Chan, Ho, Tsang, Lee, \& Chung, 2006; Ho, Ng, \& Ng, 2003; McBride-Chang \& Ho, 2005; Shu, McBrideChang, Wu, \& Liu, 2006). In two recent attempts where these four important 
Yeung et al.: Predictors of Chinese reading and spelling

reading-related skills were examined in the same context, rapid naming, orthographic skills, and morphological awareness uniquely explained variance in concurrent Chinese word reading and writing to dictation (i.e., spelling) among kindergarteners (Tong, McBride-Chang, Shu, \& Wong, 2009) and Grade 1 students (Yeung et al., 2011) in Hong Kong. However, longitudinal data on Chinese word reading and spelling, especially among early elementary grades students, are lacking in the literature, making it difficult to examine the predictive power of the reading-related skills over time. Some models on reading and spelling acquisition suggest that there are differences in the relative importance of skills involved in learning to read and spell in different grades. Does the same situation apply to Chinese word reading and spelling development?

\section{MODELS OF READING AND SPELLING DEVELOPMENT IN ALPHABETIC LANGUAGES}

There are two main approaches to the study of reading and writing development. One is the stage or phase approach, which conceptualizes children's knowledge and strategies of reading and writing as distinctly different at different points in time (e.g., Ehri, 1992; Frith, 1980; Gentry, 1982). The other approach views children's reading and spelling development as gradual buildup of different types of knowledge and strategies in a more continuous manner (Varnhagen, McCallum, \& Burstow, 1997).

The three-phase model proposed by Frith $(1980,1985)$ is a classic work to explain the reading development in alphabetic languages in a stagelike fashion. In the first logographic phase, children are supposed to identify words as unanalyzed whole images and to recognize words on the basis of some salient graphic features that are not necessarily letters. It is only in the next phase, the alphabetic phase, that children begin to make use of letter identity and order to recognize words. Eventually, instead of relying on one-to-one correspondence decoding strategy, children acquire and utilize more complex orthographic knowledge, with letter groups as units of analysis and higher-order condition rules, without phonological conversion to identify words in the last phase, called orthographic phase. Other proposals on the stages of lexical development expanded more on the stages involving the acquisition of grapheme-phoneme correspondence knowledge (Ehri \& Wilce, 1985; Gough \& Hillinger, 1980; Mason, 1980) and are compatible with Frith's three-phase model.

Frith $(1980,1985)$ has claimed that spelling development also involves three main phases, similar to those of reading. Spelling is first restricted to a few rote words in the logographic phase, which is followed by an alphabetic phase in which decoding takes place. Finally, decoding is increasingly replaced by lexical analogies in the orthographic phase. Other researchers proposed that spelling development involves five characteristic stages (Joshi \& Aaron, 2003), namely, precommunicative, semiphonetic, phonetic, transitional, and correct/morphophonemic (Gentry, 1982; Moats, 1995). In general, an earlier developmental stage marked by phonological analysis is followed by a stage based on lexical analogies (Lennox \& Siegel, 1994). 
Yeung et al.: Predictors of Chinese reading and spelling

\section{Skills important to learning to read and spell in alphabetic languages over time}

According to the stage models of reading and spelling development, the dominant strategy for each stage differs. The significance of different cognitive-linguistic skills to reading and spelling performance is likely to differ in different stages. For example, visual skills (e.g., Kavale \& Forness, 2000) and rapid naming skills (e.g., Bowers \& Swanson, 1991; Wagner et al., 1997), which involve direct access of simple visual forms and the corresponding sound codes, should be more significant in early stage, such as the logographic stage. Phonological skills should be of paramount importance in the alphabetic stage, where phonological strategies dominate (e.g., Bradley \& Bryant, 1983, 1985; Wagner et al., 1997). Research shows that children's performance in phonological awareness tasks, assessing "the ability to perform mental operations on the output of the speech perception mechanism" (Tunmer \& Chapman, 1998, p. 366), is strongly related to success in reading and spelling (e.g., Adams, 1990; Goswami \& Bryant, 1990; Rego \& Bryant, 1993; Wagner \& Torgesen, 1987). The most advanced stage, the consolidated alphabetic phase or orthographic stage, should then be marked by the prevalence of orthographic skills (Barker, Torgesen, \& Wagner, 1992; Cunningham \& Stanovich, 1991; Roman, Kirby, Parrila, Wade-Woolley, \& Deacon, 2009).

Still, some researchers found that the stages are not that distinct and simple, and thus the relationships between various cognitive-linguistic skills and reading and spelling development are not that straightforward. Recent research supports a more interactive approach in which different sources of information and strategies work in parallel, instead of occurring as a clear sequence of separate stages (Aaron \& Joshi, 1992; Brown \& Ellis, 1994; Perfetti, Rieben, \& Fayol, 1997; Sterling \& Robson, 1992). Children are likely to make use of all the strategies and knowledge available to them in learning to read and spell. For example, Marsh, Friedman, Welch, and Desberg (1980) showed that children used analogies, which should be the characteristic of the orthographic stage, in their judgment of words as early as Grade 2. In studying Chinese children in Grades 2, 4, and 6 learning to read English words, Yin, Anderson, and Zhu (2007) found that the use of orthographic analogy does not form a separate independent stage but is a concurrent strategy available even among the very young children. In examining the spelling samples of children in first through sixth grade, Varnhagen et al. (1997) found little evidence for a qualitative change property of a stagelike theory for children's spelling development. Phonological, orthographic, and morphological spelling strategies were evident in children at all grade levels. The main differences across grades were the proportions of the different types of errors. Findings in experiments investigating children's progression from initial attempts at spelling nonwords to direct retrieval of the spellings later also showed that the trajectories for individual children are more variable than expected by a stage theory (Kwong \& Varnhagen, 2005). These results were in line with the conceptualization of the overlapping waves theory (cf. Rittle-Johnson \& Siegler, 1999; Siegler, 1995). Children are thought to possess different types of knowledge and strategies even from a very early age. They shift their reliance on different strategies as they learn more about the effectiveness of different strategies over time (Kwong \& Varnhagen, 2005). In general, there was 
Yeung et al.: Predictors of Chinese reading and spelling

increasing support for the notion that reading and spelling development can better be understood in terms of the development of interrelated knowledge and strategies.

\section{Differences between reading and spelling}

The similarities in the proposals about the stages of reading and spelling development in alphabetic languages are so evident that it was widely assumed that the processes behind reading and spelling among children are almost the same. Later some researchers started to acknowledge and to find subtle differences in the processes behind these two highly correlated literacy skills. For example, it was found that younger children are more ready to adopt a phonological strategy to spell than to read. Bryant and Bradley (1980) showed that 6- and 7-year-old children were better in spelling phonologically regular words than in reading them, reflecting children's heavier reliance on a phonological strategy in spelling than in reading. In another study with participants of roughly the same age range, Bryant and Bradley (1983) found that phonological interference impaired children's performance in spelling task but not word reading task, which lends support to the notion that children rely on a phonological strategy to spell but not to read. Snowling (1994) also argued that young children do make use of their limited phonological skills from an early stage of spelling.

\section{CHARACTERISTICS OF THE CHINESE WRITING SYSTEM}

Because the reader may not be familiar with the Chinese language, we will first briefly describe the main characteristics of the Chinese orthography. The basic graphic unit in Chinese is a character. Each character represents a syllable as well as a morpheme. There are about 4,600-4,900 commonly used Chinese characters in Hong Kong (Cheung \& Bauer, 2002; Lee, 2000). Chinese characters are made up of different strokes. Strokes are combined to form stroke patterns. The number of strokes in a Chinese character is a measure of its visual complexity. The average number of strokes of the 2,000 commonly used characters is 11.2 for the traditional script used in Hong Kong and Taiwan and 9.0 for the simplified script used in mainland China (Chan, 1982). There are some stroke order rules in writing Chinese characters. Memory of these character stroke orders is important for character spelling in Chinese. Strokes are the basic building components of radicals, which are combined in different configurations to produce the characters (Shen \& Bear, 2000). It is thus expected that the orthographic knowledge important for character spelling in Chinese includes at least three levels: stroke (including stroke order), radical, and configuration.

About $80 \%$ to $90 \%$ of Chinese characters are ideophonetic compounds, each comprising a semantic radical and a phonetic radical (Kang, 1993). In general, the semantic radical in a Chinese character signifies the semantic category of the character. According to Chung and Leung (2008), 33\% of the semantic-phonetic compound characters encountered by Grade 1 students in Hong Kong were transparent (e.g., the character 媽, “mother," with the semantic radical 女, "female"), $22 \%$ were semitransparent (e.g., the character 枯, "decay," with the 
semantic radical 木, “plant”), and 30\% were opaque (e.g., the character 增, "increase," with the semantic radical 土, "soil"). The semantic radical often occupies a habitual position in a Chinese character, which is left or top. The sound of a Chinese character can be derived directly from its phonetic radical or indirectly by making an analogy with other characters having the same phonetic radical. The predictive accuracy of the pronunciation of an ideophonetic compound character from its phonetic radical is about $40 \%$ (Shu, Chen, Anderson, Wu, \& Xuan, 2003; Zhou, 1980; Zhu, 1987). This drops to $23 \%$ to $26 \%$ if tone is taken into consideration (Chung \& Leung, 2008; Fan, 1986; Shu et al., 2003; Zhou, 1980). Overall, semantic radicals are functionally more reliable than phonetic ones.

Many words in Chinese are formed by combining different morphemes, (e.g., "foot-ball," "basket-ball," "hand-ball"), and we may derive the meaning of the whole word from its constituent morphemes. Given the characteristics of the large number of homophones and word compounding in Chinese, an awareness of morphemes is particularly important in learning to read Chinese (McBride-Chang, Wagner, Muse, Chow, \& Shu, 2005).

\section{Skills important to word reading and spelling in Chinese}

In view of the differences between the Chinese and alphabetic writing systems in the way they represent sound and meaning, cognitive-linguistic skills that are important in learning to read and write Chinese words are expected to be different from those found in alphabetic writing systems. A Chinese character is simultaneously a visual whole, a syllabic unit, and a morpheme, which contrasts with the units of writing in alphabetic scripts, letters, which indicate sound only and have no dovetailed relation with meaning (Hoosain, 1991). With the script-soundmeaning convergence of the Chinese character, orthographic skills and morphological awareness are expected to be of particular importance in Chinese reading and spelling development. Chinese children would rely less on phonological skills than English children in both reading and spelling. On reviewing the findings of previous studies in Chinese, rapid naming, orthographic skills, and morphological awareness were found to explain a significant amount of variance in Chinese word reading and spelling among children in a wide age range (from kindergartens to elementary grades) whereas the significance of phonological awareness in Chinese word reading and spelling development seems to be more time limited.

Phonological awareness predicts very early reading in Chinese (e.g., Ho \& Bryant, 1997a; McBride-Chang \& Ho, 2005). Ho and Bryant (1997a) found that rhyme awareness was significantly correlated with Chinese ideophonetic compound reading among first graders in Hong Kong. Phonological awareness of preschool children predicted reading success at around age 5 to 7 among Hong Kong Chinese preschool children in a 4-year longitudinal study by Ho and Bryant (1997b). However, phonological awareness was not a significant predictor of Chinese word reading among first graders after controlling for rapid naming, orthographic skills, and morphological awareness (Tong et al., 2009; Yeung et al., 2011). McBride-Chang et al. (2005) also showed that phonological awareness did not significantly predict second graders' Chinese word recognition after controlling for vocabulary and morphological awareness. Another phonological 
skill that is related to reading development in alphabetic languages is phonological memory (Gathercole \& Baddeley, 1989; Gathercole, Willis \& Baddeley, 1991; Gathercole, Willis, Emslie, \& Baddeley, 1992). There were far fewer studies on its role in Chinese word reading, and the findings were not consistent. For example, phonological memory was not a significant predictor of Chinese character reading among kindergartners in the longitudinal study by McBride-Chang and Ho (2005). In contrast, the study among Grades 1 to 4 students by Chan et al. (2006) showed that phonological memory was a significant predictor of Chinese word reading and spelling in the same context with rapid naming, orthographic skills, and phonological awareness. Due to the absence of direct symbol-sound correspondence in Chinese (Perfetti \& Tan, 1998), the role of a phonological recoding strategy and that of phonological skills, including phonological awareness and phonological memory, are expected to be relatively limited in Chinese word reading and spelling.

Instead, rapid naming, which in part taps the ability for learning arbitrary associations between sound and script, was a robust predictor of Chinese word reading among kindergarten and elementary grade students (Chan et al., 2006; McBride-Chang \& Ho, 2005; Shu et al., 2006; Tong et al., 2009; Yeung et al., 2011). This seems to be inconsistent with the suggestion that rapid naming was a prereading skill that contributes significantly to orthographic skills development (Manis, Doi, \& Bhadha, 2000) and the finding that its importance was taken up by orthographic skills in advanced grades among English-speaking children (Roman et al., 2009). However, no conclusions can yet be made with reference to previous findings. Though rapid naming was a strong predictor of Chinese word reading and spelling among Grades 1 to 4 students in the study by Chan et al. (2006) and Grades 5 to 6 students in the study by Shu et al. (2006), data from students of different grades were combined in the analyses in the former and orthographic skills was not included in the latter.

According to Castles and Nation (2006), orthographic processing skills refer to the sensitivity to orthographic regularities in the language. Whereas children learning to read alphabetic languages have to pay attention to the regularities of letter combination, children learning to read Chinese need to be sensitive to the regularities of character structure and the orthosemantic and orthophonological regularities of the radicals. Knowledge of character structure was a salient predictor of Chinese character reading and spelling among participants from kindergarten to Grade 4 in Hong Kong (Chan et al., 2006; Ho, Chan, Chung, Lee, \& Tsang, 2007; McBride-Chang \& Ho, 2005; Tong et al., 2009). Ho et al. (2003) extensively investigated Chinese children's radical knowledge (both positional and functional) among Grade 1 to Grade 5 children. They showed that various types of semantic radical and phonetic radical knowledge were significantly correlated with Chinese word reading. Radical knowledge, a kind of orthographic skill, was still a significant predictor of Chinese word reading and spelling after controlling for rapid naming, phonological awareness, and morphological awareness among first graders (Yeung et al., 2011).

Similar to the situation found among English-speaking children (Carlisle, 1995; Roman et al., 2009), morphological awareness seems to be related to both early and late reading development among Chinese children (McBride-Chang, Shu, Zhou, Wat, \& Wagner, 2003; McBride-Chang et al., 2005; Shu et al., 2006; Tong et al., 
Yeung et al.: Predictors of Chinese reading and spelling

2009; Yeung et al., 2011). The major difference between the studies of the two languages is the conceptualization of morphological awareness in each language. In view of the prevalence of homophones and the fact that the component morphemes of multicharacter Chinese words are important cues to their meaning (Hoosain, 1991), children's morphological awareness, including the ability to distinguish among meanings of homophones and morpheme construction skills, should be important to learning to read and spell Chinese words. The study by Shen and Bear (2000) was one of the few studies examining Chinese spelling development. By analyzing the invented spellings from spontaneous samples as well as spelling tests among Chinese children in Grade 1 to Grade 6 in mainland China, they found that phonological strategies predominate in the lower elementary grades but the use of graphemic and semantic strategies increases as grade level advances. A greater overlap in the development of graphemic and semantic knowledge was found in Chinese spelling than there is in English and thus qualitative different stages are less obvious in Chinese spelling development. This suggests that orthographic skills and morphological awareness are likely to be more important in Chinese spelling in advanced grades. Unlike children in mainland China, children in Hong Kong learn to read and write Chinese words without the assistance of any phonetic system. It is thus expected that phonological skills may not play a predominant role in early elementary grades among Hong Kong children.

\section{AIM OF THE PRESENT STUDY}

The fact that most of the above-mentioned studies were conducted among children of a particular age range and employed different measures for the same type of skills makes it difficult to draw conclusions regarding the relative predictive power of each reading-related skill in Chinese word reading and spelling across different grades and over time. The main aim of the present study was to address this problem by conducting a 3 -year longitudinal study to track the word reading and spelling development of a group of students from Grade 1 to Grade 4 . Based on the previous findings on kindergarteners and Grade 1 students, it was hypothesized that rapid naming was a strong predictor of Chinese word reading and spelling in younger children. However, its importance was expected to be taken up by orthographic skills in more advanced grades with reference to the suggestion of the close relationship between rapid naming and orthographic skills (Manis et al., 2000). Based on previous findings and the characteristics of the Chinese writing system, orthographic skills and morphological awareness were expected to be significant predictors of Chinese word reading and spelling across grades, whereas phonological skills was expected to play a relatively limited role in learning to read and spell Chinese, especially in higher grades.

\section{METHOD}

\section{Participants}

At the beginning of the study, 271 Grade 1 Chinese children (133 boys and 138 girls) were recruited from two representative primary schools in Hong Kong to participate. The reading and spelling development of these children was followed 
from Grade 1 (Time 1) to the beginning of Grade 4 (Time 3) in a 3-year longitudinal study. Twenty participants ( 14 boys and 6 girls) dropped out by Time 3 . Eventually, 251 participants (119 boys and 132 girls) remained in the study at the beginning of Grade 4 with a dropout rate of $7.38 \%$. Multivariate analysis of variance results showed that the participants who dropped out by Time 3 and those who remained in the study did not differ significantly on age, IQ, or other measures at Time 1, Wilks $\lambda=0.956, F(10,260)=1.207, p=.287$. The same pattern of results was revealed by $t$ test analyses ( $t \mathrm{~s}<1.617, p \mathrm{~s}>.05$ ). The mean IQ scores of the children were $110(S D=14.19)$ and the mean age of the children was 6.82 years $(S D=0.32$ years) at Time 1. Both schools used Cantonese as the medium of instruction for Chinese language lessons. Children in Hong Kong encountered about 1,300 new Chinese characters in Grade 1 (36\% of all the new Chinese characters they are to learn in elementary grades) and around 500-600 new characters each year in Grades 2 to 4 (Chung \& Leung, 2008). Children in Hong Kong mostly learn to read Chinese characters with a "look and say" method, and there is no phonetic system, like pinyin in mainland China, to assist Chinese character learning. In traditional classroom, teachers teach writing by demonstrating writing each character stroke by stroke on the blackboard, and students learn by copying the character, following the stroke order presented by the teachers (Packard et al., 2006). Unlike spelling in English, there is no nameable component (e.g., alphabet) in Chinese. The children were assessed on reading-related skills from the middle to the end of Grade 1 (Time 1). Their performance in word reading and spelling was measured at Time 1, at the end of Grade 2 (Time 2), and at the beginning of Grade 4 (Time 3). The children did not have experience with most of the tasks administered, except for word reading and spelling. Instructions and examples were repeated until the children understood how to do each task. To ensure that the children were familiar with the tasks, practice trials were given before the testing trials.

\section{Measures}

\section{General intellectual ability.}

RAVEN'S STANDARD PROGRESSIVE MATRICES. This is a standardized test (Raven, 1958) for measuring nonverbal intelligence. The test included five sets of 12 items each, which is a total of 60 items. Each item consisted of a target visual matrix with a missing piece. The children were required to pick, from six to eight alternatives, the best part to complete the target matrix. The test was conducted at Time 1. The short form of the test, made up of the first three sets of the full form, was administered to children who were less than 8.5 years old in the present study. Scoring procedures were based on the local norm established by the Education Department of the Hong Kong government in 1986.

\section{Oral language skills.}

ORAL VOCABULARY. This task was developed to measure the expressive vocabulary of the children at Time 1. A colored picture of a classroom scenario was presented to the children. They were instructed to name the objects and to 
Yeung et al.: Predictors of Chinese reading and spelling

describe what was happening in the picture. Each word that was relevant to the scenario was given one mark. Repeated tokens of the same answer were not given additional marks.

Rapid naming. Children's rapid automatized naming (Denckla \& Rudel, 1976) was measured by a rapid digit naming task because alphanumeric naming speed was a better predictor of word reading than nonalphanumeric naming speed (Bowey, McGuigan, \& Ruschena, 2005). The digits (1, 2, 5, 6, and 8) were printed in a $5 \times 8$ matrix on A4 paper. The participants were instructed to name the digits from left to right and from top to bottom as quickly and accurately as possible. They were asked to name the list twice. The average latency across the two trials was computed to the nearest $1 / 100 \mathrm{~s}$ and the errors were recorded.

\section{Phonological skills.}

PHONOLOGICAL AWARENESS. A task modeled after the rhyme detection subtest of the Hong Kong Test of Specific Learning Difficulties in Reading and Writing (HKT-SpLD; Ho, Chan, Tsang, \& Lee, 2000) was used to assess rhyme awareness of the children. In each trial, the children were presented with three Chinese syllables through a computer audio system, along with their corresponding pictures to ease their memory load. The two target syllables shared the same rhyme, whereas the rhyme of the distractor syllable differed from that of the target syllables. The tone of the three syllables in each trial was the same, whereas the onsets were different. The children were asked to choose the target answers by circling the corresponding pictures. There were 12 testing items. One mark was given for the correct answers in each trial.

PHONOLOGICAL MEMORY. A modified version of the nonword repetition subtests of the HKT-SpLD (Ho et al., 2000) was used to measure the phonological memory of the children. Eight sequences of legal Chinese syllables, ranging from four to seven syllables long, were presented in order of ascending length. In each sequence, syllables were of identical tone but varied in onsets and rhymes. The stimuli were presented through mp3 players to the children. A practice trial with the length of three syllables was given prior to the testing trials. In each testing trial, the children were required to orally repeat the syllables in the order presented. All stimuli were presented once. One mark was given for each successfully recalled syllable and one mark was given to each correct order of recall between two successive syllables. One mark was deducted for any extra syllable produced.

\section{Orthographic skills.}

PSEUDOCHARACTER MEANING JUDGMENT. This task was adapted from Ho et al.'s (2003) study to measure the children's overall awareness of positions, functions, and semantic categories of different Chinese semantic radicals. Each pseudocharacter was composed of a semantic radical and a phonetic radical in their legal positions, but the combination was not a real Chinese character. Both lexical and nonlexical semantic radicals were used to construct pseudocharacters. In each 
Yeung et al.: Predictors of Chinese reading and spelling

trial, a pseudocharacter was presented together with four pictures side by side. Each picture held a semantic association with a common semantic radical. The participants were asked to circle the target picture that held a semantic association with the target semantic radical. There were 16 testing items. One mark was given for the correct answer to each item.

PHONOLOGICAL-RELATEDNESS JUDGMENT. This task was also adapted from Ho et al.'s (2003) study to measure the children's awareness of the function of phonetic radicals. Pseudocharacters were constructed the same way as in the pseudocharacter meaning judgment task. In each item, a target pseudocharacter was presented together with three choice characters, from which the children were to select the one that might have the same or similar pronunciation as the target pseudocharacter. The three choice characters were a character sharing the same semantic radical with the target pseudocharacter, a character sharing the same phonetic radical (the correct answer), and a control character. There were 18 testing items. One mark was given for the correct answer to each item.

\section{Morphological awareness.}

HOMOPHONE AWARENESS. This task was modeled after the Morpheme Identification Test (McBride-Chang et al., 2003) and was used to assess children's ability to differentiate different morphemes in homophones. In each item, three two-syllable Chinese words were orally presented to the children in Cantonese, and the words had an identical syllable at the same position. For example, the words [naam4] [tsi3] (男廁, male washroom), [naam4] [dzai2] (男仔, young boy), and [naam4] [gik9] (南極, South Pole) shared the same syllable [naam4]. The syllable in the first two words shared the same meaning of male, whereas the syllable in the last word had a meaning of south. The children were asked to identify the two words that had a syllable sharing the same meaning and circle the numbers $(1,2$, or 3$)$ assigned to the words according to the presentation order. To prevent children from judging the meaning of the orally presented words by thinking of their written form, unfamiliar words based on the Hong Kong Corpus of Primary School (Leung \& Lee, 2002) were used. Two practice trials were given, and there were 15 testing items. One mark was given for the correct answer to each item. The positions of the target syllables in the words and the order of correct answers were counterbalanced across items.

MORPHOLOGICAL CONSTRUCTION. This task was adapted from McBrideChang and colleagues' studies $(2003,2005)$ to measure morphological structure awareness of the children. In each item, a novel object or concept was presented orally with a scenario in the form of a two- to three-sentence story. The children were asked to construct new compound words for the novel objects or concepts based on previously learned morphemes. Each compound word included two to four morphemes. Each answer was given 0, 1, or 2 marks. For example, "If we called a flower (花 [faal]) that is big (大 [daai6]) and yellow (黃 [wong4]) as Big-yellow-flower (大黃花 [daai6][wong4][faal]), what should we call a flower that is big and purple (紫 $[d z i 2])$ ?" The correct answer for this item should be 
Big-purple-flower (大紫花 [daai6] [dzi2] [faal]) and was given 2 marks. An answer that contained all major morphemes but did not conform completely to the morpheme construction rules (e.g., in this case, 紫大花, [dzi2] [daai6] [faal]) was given 1 mark. Two practice trials were given before the testing trials. There were 12 testing items.

\section{Literacy measures.}

WORD READING. The Chinese Word Reading subtest of the HKT-SpLD (Ho et al., 2000) was used to assess the children's word reading performance at Time 1, Time 2, and Time 3. The children were asked to read aloud 150 Chinese twocharacter words in the order of graded difficulty. The test was discontinued when the child failed to read 15 words consecutively. One mark was given to each word correctly read.

WORD SPELLING (I.E., DICTATION). Participants' word writing to dictation skill was assessed by a Chinese word spelling task consisting of two-character Chinese words selected from popular Chinese textbooks for each grade in Hong Kong. There were 13, 10, and 11 two-character words in the word spelling task for Times 1 to 3 , respectively. In each trial, the participants were asked to write down the target word, which was read aloud three times by the experimenter: first in isolation, then embedded in a simple sentence, and finally on its own again. One mark was given for each correctly written character.

\section{Procedures}

All the measures were administered to the children by trained research assistants. Apart from the rapid naming, phonological memory, oral vocabulary, morphological construction, and word reading tasks, all other measures were administered in groups. Each testing session, either individual or group, lasted for about 20 to $60 \mathrm{~min}$.

\section{RESULTS}

\section{Descriptive analyses}

Table 1 presents the means, standard deviations, reliability coefficients, and ranges for the tasks undertaken in this study. In general, the reliability of the tasks in this study was acceptable with reliability coefficients ranging from 0.63 to 0.96 for most tasks, except for phonological awareness, with a reliability coefficient of 0.50 .

\section{Correlation}

Table 2 shows the correlations among age, IQ, oral vocabulary, the reading-related skills, and literacy measures in the study. Most of the correlations among the reading-related skills measures were statistically significant, except that between 
Yeung et al.: Predictors of Chinese reading and spelling

Table 1. Reliabilities, means, standard deviations, and ranges for measures in the present study

\begin{tabular}{|c|c|c|c|c|c|}
\hline Variable & $\begin{array}{l}\text { Reliability } \\
\text { Coefficient }\end{array}$ & Mean & $S D$ & Range & $\operatorname{Max}$ \\
\hline Age (months) (Time 1) & & 81.93 & 3.77 & 76-94 & \\
\hline IQ (Time 1) & & 110.13 & 14.19 & $65-135$ & \\
\hline Oral vocabulary (Time 1) & .96 & 13.70 & 4.53 & $2-32$ & \\
\hline Rapid naming (s) (Time 1) & .89 & 23.48 & 5.67 & $13.41-43.34$ & \\
\hline \multicolumn{6}{|l|}{ Phonological } \\
\hline Awareness (Time 1) & .50 & 7.38 & 2.16 & $2-12$ & 12 \\
\hline Memory (Time 1) & .81 & 45.48 & 15.16 & $0-68$ & \\
\hline \multicolumn{6}{|l|}{ Pseudocharacter meaning } \\
\hline $\begin{array}{l}\text { judgment (Time 1) } \\
\text { Phonological-relatedness }\end{array}$ & .63 & 9.92 & 2.87 & $3-16$ & 16 \\
\hline judgment (Time 1) & .76 & 13.14 & 3.41 & $2-18$ & 18 \\
\hline $\begin{array}{l}\text { Homophone awareness } \\
\text { (Time 1) }\end{array}$ & .63 & 11.21 & 2.55 & $3-15$ & 15 \\
\hline $\begin{array}{l}\text { Morphological construction } \\
\text { (Time 1) }\end{array}$ & .68 & 15.12 & 4.32 & $2-24$ & 24 \\
\hline \multicolumn{6}{|l|}{ Word reading } \\
\hline Time 1 & $\mathrm{~S}$ & 70.92 & 26.59 & $4-136$ & 150 \\
\hline Time 2 & S & 99.20 & 21.28 & $17-144$ & 150 \\
\hline Time 3 & $\mathrm{~S}$ & 118.17 & 16.84 & $35-148$ & 150 \\
\hline \multicolumn{6}{|l|}{ Word spelling } \\
\hline Time 1 & .83 & 11.31 & 4.92 & $0-22$ & 26 \\
\hline Time 2 & .81 & 13.11 & 4.19 & $1-20$ & 20 \\
\hline Time 3 & .84 & 14.24 & 4.81 & $0-22$ & 22 \\
\hline
\end{tabular}

Note: Interrater reliability coefficient was computed for oral vocabulary. Test-retest reliability was computed for rapid naming. Cronbach alpha coefficients were computed for phonological awareness, phonological memory, pseudocharacter meaning judgment, phonological-relatedness judgment, homophone awareness, morphological construction, and word spelling. S, standardized measure with good reported reliability.

rapid naming and phonological-relatedness judgment, and that between phonological awareness and phonological memory. The significant correlation coefficients among the reading-related skills were in the range of .13 to .45 , reflecting low to medium strength of relationships. The literacy measures were more highly correlated with one another $(r s>.38, p s<.001)$. Most of the correlations between the reading-related skills and Chinese literacy measures were significant $(r s>.18$, $p$ s $<.01$ ), except that between phonological-relatedness judgment and Time 2 word spelling.

\section{Multiple regression analyses}

To examine the two research questions about the unique contribution of each reading-related skill to Chinese word reading and spelling across time, a number 
Table 2. Correlations among all variables in this study

\begin{tabular}{|c|c|c|c|c|c|c|c|c|c|c|c|c|c|c|c|c|}
\hline & \multirow[b]{2}{*}{ Age } & \multirow[b]{2}{*}{ IQ } & \multirow[b]{2}{*}{ OV } & \multirow[b]{2}{*}{ RAN } & \multirow[b]{2}{*}{ PA } & \multirow[b]{2}{*}{ PM } & \multirow[b]{2}{*}{ OKS } & \multirow[b]{2}{*}{ OKP } & \multirow[b]{2}{*}{ HA } & \multirow[b]{2}{*}{ MC } & \multicolumn{3}{|c|}{ WR } & \multicolumn{3}{|c|}{ WS } \\
\hline & & & & & & & & & & & $\mathrm{T} 1$ & $\mathrm{~T} 2$ & $\mathrm{~T} 3$ & $\mathrm{~T} 1$ & $\mathrm{~T} 2$ & $\mathrm{~T} 3$ \\
\hline Age & - & & & & & & & & & & & & & & & \\
\hline IQ & -.05 & - & & & & & & & & & & & & & & \\
\hline OV & .06 & .09 & - & & & & & & & & & & & & & \\
\hline RAN & -.01 & -.09 & .02 & - & & & & & & & & & & & & \\
\hline PA & .15 & .14 & -.10 & -.16 & - & & & & & & & & & & & \\
\hline PM & .13 & .26 & .13 & -.13 & .10 & - & & & & & & & & & & \\
\hline OKS & .10 & .40 & .02 & -.25 & .17 & .28 & - & & & & & & & & & \\
\hline OKP & .09 & .17 & -.10 & -.09 & .16 & .21 & .28 & - & & & & & & & & \\
\hline HA & .06 & .37 & .04 & -.19 & .22 & .24 & .41 & .16 & - & & & & & & & \\
\hline MC & .18 & .46 & .07 & -.19 & .22 & .39 & .45 & .25 & .39 & - & & & & & & \\
\hline WR (T1) & .05 & .32 & .02 & -.48 & .19 & .29 & .49 & .24 & .43 & .42 & - & & & & & \\
\hline WR (T2) & .04 & .30 & .04 & -.45 & .22 & .35 & .47 & .23 & .41 & .44 & .91 & - & & & & \\
\hline WR (T3) & .03 & .29 & .03 & -.40 & .19 & .29 & .46 & .21 & .42 & .45 & .86 & .94 & - & & & \\
\hline WS (T1) & .07 & .23 & .04 & -.28 & .23 & .27 & .37 & .23 & .45 & .39 & .55 & .57 & .54 & - & & \\
\hline WS (T2) & .11 & .22 & .01 & -.25 & .23 & .22 & .31 & .11 & .27 & .27 & .38 & .42 & .42 & .58 & - & \\
\hline WS (T3) & .09 & .23 & .00 & -.25 & .23 & .29 & .41 & .18 & .30 & .31 & .49 & .54 & .55 & .63 & .67 & - \\
\hline
\end{tabular}

Note: OV, oral vocabulary; RAN, rapid naming; PA, phonological awareness; PM, phonological memory; OKS, pseudocharacter meaning judgment; OKP, phonological-relatedness judgment; HA, homophone awareness; MC, morphological construction; WR, word reading; WS, word spelling; T1, Time 1; T2, Time 2; T3, Time 3. For all variables, $N=251$; correlations of magnitude .13 are significant at $p<.05$. 
Yeung et al.: Predictors of Chinese reading and spelling

of hierarchical multiple regression analyses were conducted. Table 3, Table 4, and Table 5 show the results of these analyses with Chinese word reading and word spelling as the dependent variables. In each regression equation, the control variables of age, IQ scores, and oral vocabulary were entered in the first step. Three of the four variables (rapid naming, phonological skills, orthographic skills, and morphological awareness), which were all assessed at Time 1, were entered into the second step. One particular reading-related skill was entered into the third step in each equation. The four reading-related skills together accounted for 35\%, $F(7,240)=22.04, p<.001 ; 34 \%, F(7,240)=21.03, p<.001 ;$ and $31 \%, F$ $(7,240)=17.83, p<.001$, of the variance in word reading at Time 1 , Time 2 , and Time 3, respectively. As for word spelling, the reading-related skills together contributed $26 \%, F(7,240)=13.17, p<.001 ; 12 \%, F(7,240)=5.08, p<$ .001 ; and $19 \%, F(7,240)=8.69, p<.001$, of the variance in it at Time 1 , Time 2 , and Time 3, respectively. After controlling for other variables, rapid naming, orthographic skills, and morphological awareness each made significant unique contribution to word reading concurrently at Time 1 and subsequently at Time 2 and Time 3. Phonological skills contributed a significant, though small (2\%), amount of unique variance of word reading at Time 2 but not at Time 1 or Time 3 .

After controlling for the effects of other variables, rapid naming consistently explained a small but significant amount of variance $(1 \%-2 \%)$ to word spelling at Time 1, Time 2, and Time 3. Phonological skills explained a significant amount of variance in word spelling at Time 2 and Time 3 but not at Time 1. On the contrary, morphological awareness contributed a substantial amount of unique variance to word reading, $9 \%, F(2,240)=14.98, p<.001$, at Time 1 but not at Time 2 or Time 3. As for orthographic skills, it contributed a marginally significant amount of variance to word spelling, $2 \%, F(2,240)=3.03, p=.05$, at Time 1 and a significant amount of variance to word spelling, $4 \%, F(2,240)=7.19, p<$ .001 , at Time 3. To sum up, rapid naming and morphological awareness were significant predictors of Time 1 word spelling. Rapid naming, phonological skills, and orthographic skills were significant predictors of Time 2 and Time 3 word spelling.

To examine the stability and change of the predictive power of Time 1 readingrelated skills on Chinese word reading and spelling over time, two series of path analyses (one on Chinese word reading and one on Chinese word spelling) were conducted using LISREL 8.80, a structural equation modeling program. In these path analyses, direct paths from each Time 1 reading-related skill to Time 1, Time 2, and Time 3 word reading and spelling were postulated. Autoregressor effects, the contribution from Chinese word reading and spelling in earlier time points, were also incorporated. Because the phonological-relatedness judgment task was not a significant predictor of either Chinese word reading or spelling in the multiple regression analyses, it was not included in the path analyses. Orthographic skills were represented by the pseudocharacter meaning judgment task. Morphological awareness was represented by the average $z$ scores of the two measures of morphological awareness (homophone awareness and morphological construction) because they both were significant predictors of Chinese word reading and spelling in the multiple regression results analyses. Path diagrams on the longitudinal predictability of Time 1 reading-related measures on 
Table 3. Summary of hierarchical multiple regression equations predicting Time 1, Time 2, and Time 3 word reading and word spelling from Time 1 reading-related cognitive skills measures after controls for differences in age, $I Q$, and oral vocabulary $(N=251)$

\begin{tabular}{|c|c|c|c|c|c|c|c|c|c|c|c|c|c|}
\hline & & \multicolumn{6}{|c|}{ Word Reading } & \multicolumn{6}{|c|}{ Word Spelling } \\
\hline & & \multicolumn{2}{|c|}{ Time 1} & \multicolumn{2}{|c|}{ Time 2} & \multicolumn{2}{|c|}{ Time 3} & \multicolumn{2}{|c|}{ Time 1} & \multicolumn{2}{|c|}{ Time 2} & \multicolumn{2}{|c|}{ Time 3} \\
\hline & & $\Delta R^{2}$ & $R^{2}$ & $\Delta R^{2}$ & $R^{2}$ & $\Delta R^{2}$ & $R^{2}$ & $\Delta R^{2}$ & $R^{2}$ & $\Delta R^{2}$ & $R^{2}$ & $\Delta R^{2}$ & $R^{2}$ \\
\hline Step 1 & Age, IQ (Raven's), \& OV & $.11 * * *$ & .11 & $.09 * * *$ & .09 & $.08 * * *$ & .08 & $.06 * *$ & .06 & $.07 * * *$ & .07 & $.06 * *$ & .06 \\
\hline Step 2 & OS, MA, \& PS & $.24 * * *$ & .35 & $.26 * * *$ & .35 & $.26 * * *$ & .34 & $.24 * * *$ & .30 & $.10 * * *$ & .17 & $.18 * * *$ & .24 \\
\hline Step 3 & RAN & $.11 * * *$ & .46 & $.09 * * *$ & .44 & $.06 * * *$ & .40 & $.02 *$ & .32 & $.02 *$ & .19 & $.01 *$ & .25 \\
\hline Step 2 & OS, MA, \& RAN & $.35 * * *$ & .45 & $.33 * * *$ & .42 & $.31 * * *$ & .39 & $.25 * * *$ & .31 & $.10^{* * *}$ & .17 & $.14 * * *$ & .21 \\
\hline Step 3 & PS & .00 & .46 & $.02 *$ & .44 & .01 & .40 & .01 & .32 & $.02 *$ & .19 & $.03 * *$ & .24 \\
\hline Step 2 & MA, PS, \& RAN & $.31 * * *$ & .41 & $.31 * * *$ & .41 & $.28 * * *$ & .37 & $.24 * * *$ & .30 & $.11 * * *$ & .17 & $.14 * * *$ & .21 \\
\hline Step 3 & OS & $.04 * * *$ & .46 & $.03 * *$ & .44 & $.03 * * *$ & .40 & $.02 \dagger$ & .32 & .01 & .19 & $.04 * * *$ & .25 \\
\hline Step 2 & OS, PS, \& RAN & $.31 * * *$ & .42 & $.31 * * *$ & .40 & $.25 * * *$ & .34 & $.18 * * *$ & .23 & $.11 * * *$ & .18 & $.18 * * *$ & .24 \\
\hline Step 3 & MA & $.04 * * *$ & .46 & $.04 * * *$ & .44 & $.06 * * *$ & .40 & $.09 * * *$ & .32 & .01 & .19 & .01 & .25 \\
\hline
\end{tabular}

Note: Raven's, Raven's Standard Progressive Matrices; OV, oral vocabulary; OS, orthographic skills, assessed by pseudocharacter meaning judgment task and phonological-relatedness judgment task; MA, morphological awareness, assessed by homophone awareness task and morphological construction task; PS, phonological skills, assessed by rhyme detection task and word repetition task; RAN, rapid naming. $\dagger p=.05 . * p<.05 . * * p<.01 . * * p<.001$. 
Table 4. Standardized betas for regression equations predicting word reading from reading-related cognitive skills measures after controls for differences in age, IQ, and oral vocabulary $(N=251)$

\begin{tabular}{|c|c|c|c|c|c|c|c|c|c|}
\hline \multirow[b]{3}{*}{ Final Step Predictors (Time 1) } & \multicolumn{9}{|c|}{ Word Reading } \\
\hline & \multicolumn{3}{|c|}{ Time 1} & \multicolumn{3}{|c|}{ Time 2} & \multicolumn{3}{|c|}{ Time 3} \\
\hline & $B$ & $S E B$ & $\beta$ & $B$ & $S E B$ & $\beta$ & $B$ & $S E B$ & $\beta$ \\
\hline Age (months) & -0.25 & 0.35 & -0.04 & -0.25 & 0.28 & -0.04 & -0.38 & 0.24 & -0.08 \\
\hline IQ & 0.08 & 0.11 & 0.05 & 0.02 & 0.09 & 0.01 & -0.02 & 0.07 & -0.02 \\
\hline Oral vocabulary & 0.03 & 0.29 & 0.01 & 0.06 & 0.23 & 0.01 & 0.04 & 0.19 & 0.01 \\
\hline Rapid naming & -1.63 & 0.24 & $-0.35 * * *$ & -1.16 & 0.19 & $-0.31 * * *$ & -0.75 & 0.16 & $-0.25 * * *$ \\
\hline \multicolumn{10}{|l|}{ Phonological } \\
\hline Awareness & 0.13 & 0.62 & 0.01 & 0.50 & 0.51 & 0.05 & 0.19 & 0.41 & 0.02 \\
\hline Memory & 0.12 & 0.09 & 0.07 & 0.19 & 0.08 & $0.14 *$ & 0.09 & 0.06 & 0.08 \\
\hline Pseudocharacter meaning judgment & 2.02 & 0.54 & $0.22 * * *$ & 1.46 & 0.44 & $0.20 * *$ & 1.19 & 0.36 & $0.20 * *$ \\
\hline Phonological-relatedness judgment & 0.56 & 0.40 & 0.07 & 0.32 & 0.32 & 0.05 & 0.22 & 0.27 & 0.04 \\
\hline Homophone awareness & 1.80 & 0.58 & $0.17 * *$ & 1.26 & 0.47 & $0.15 * *$ & 1.15 & 0.39 & $0.17 * *$ \\
\hline Morphological construction & 0.80 & 0.38 & $0.13 *$ & 0.79 & 0.31 & $0.16 *$ & 0.86 & 0.25 & $0.22 * *$ \\
\hline
\end{tabular}

$* p<.05 . * * p<.01 . * * * p<.001$. 
Table 5. Standardized betas for regression equations predicting word spelling from reading-related cognitive skills measures after controls for differences in age, $I Q$, and oral vocabulary $(N=251)$

\begin{tabular}{|c|c|c|c|c|c|c|c|c|c|}
\hline \multirow[b]{3}{*}{ Final Step Predictors (Time 1) } & \multicolumn{9}{|c|}{ Word Spelling } \\
\hline & \multicolumn{3}{|c|}{ Time 1} & \multicolumn{3}{|c|}{ Time 2} & \multicolumn{3}{|c|}{ Time 3} \\
\hline & $B$ & $S E B$ & $\beta$ & $B$ & $S E B$ & $\beta$ & $B$ & $S E B$ & $\beta$ \\
\hline Age (months) & -0.05 & 0.07 & -0.04 & 0.07 & 0.07 & 0.06 & 0.00 & 0.08 & 0.00 \\
\hline IQ & -0.02 & 0.02 & -0.06 & 0.02 & 0.02 & 0.06 & 0.00 & 0.02 & 0.00 \\
\hline Oral vocabulary & 0.04 & 0.06 & 0.03 & -0.01 & 0.06 & -0.01 & -0.02 & 0.06 & -0.02 \\
\hline Rapid naming & -0.12 & 0.05 & $-0.14 *$ & -0.11 & 0.05 & $-0.15^{*}$ & -0.10 & 0.05 & $-0.12 *$ \\
\hline \multicolumn{10}{|l|}{ Phonological } \\
\hline Awareness & 0.20 & 0.13 & 0.09 & 0.25 & 0.12 & $0.13 *$ & 0.26 & 0.13 & 0.12 \\
\hline Memory & 0.02 & 0.02 & 0.07 & 0.03 & 0.02 & 0.09 & 0.05 & 0.02 & $0.15^{*}$ \\
\hline Pseudocharacter meaning judgment & 0.19 & 0.11 & 0.11 & 0.21 & 0.10 & $0.14 *$ & 0.43 & 0.12 & $0.26 * * *$ \\
\hline Phonological-relatedness judgment & 0.12 & 0.08 & 0.08 & -0.04 & 0.08 & -0.03 & 0.02 & 0.08 & 0.02 \\
\hline Homophone awareness & 0.54 & 0.12 & $0.28 * * *$ & 0.15 & 0.11 & 0.09 & 0.17 & 0.12 & 0.09 \\
\hline Morphological construction & 0.19 & 0.08 & $0.17 *$ & 0.05 & 0.07 & 0.05 & 0.05 & 0.08 & 0.05 \\
\hline
\end{tabular}

$* p<.05 . * * p<.01 . * * * p<.001$. 
Chinese word reading and word spelling are shown in Figure 1 and Figure 2, respectively. Results from the first set of path analyses showed that rapid naming, orthographic skills, and morphological awareness have significant direct paths to Time 1 word reading. Only phonological memory has significant direct path to Time 2 word reading. The only significant direct paths to Time 3 word reading are from phonological memory and morphological awareness. One point to note was that the direct path from phonological memory to Time 3 word reading indicates a negative relationship. The direct paths from Time 1 to Time 2 word reading and from Time 2 to Time 3 word reading are significant. The direct path from Time 1 to Time 3 word reading is not significant. As for Chinese word spelling, the direct paths from rapid naming and morphological awareness to Time 1 word spelling are significant. No direct paths from the Time 1 reading-related skills to Time 2 word spelling are significant. The only reading-related skills that has a significant direct path to Time 3 word spelling is pseudocharacter meaning judgment. All the postulated paths among Time 1, Time 2, and Time 3 word spelling are significant.

To sum up, the path analyses results on word reading suggest that Time 1 rapid naming and orthographic skills contributed to subsequent word reading mainly through their influence on Time 1 word reading whereas morphological awareness had both significant direct and indirect effects on Time 3 word reading. Phonological memory had a significant positive direct effect on Time 2 word reading but a negative direct effect on Time 3 word reading. As for word spelling, rapid naming and morphological awareness contributed to subsequent word spelling mainly through their influence on Time 1 word spelling. After controlling for autoregressor effects, the only Time 1 reading-related skill that had a significant direct effect on subsequent word spelling was pseudocharacter meaning judgment.

\section{Analyses on spelling errors}

We also analyzed children's spelling errors individually. With reference to the classification system of Chinese spelling errors in Shen and Bear's (2000) study and Tong et al.'s (2009) study, spelling errors were classified into three general categories according to the linguistic principles of Chinese characters: phonologically based spelling errors, orthographic-based spelling errors, and semantic spelling errors. In the study by Tong et al. (2009), a single omission of the morpheme in a two-character word was categorized as a morpholexically based error, and it accounted for the largest percentages of the total errors $(89.5 \%$ at Time 1 and $67.1 \%$ at Time 2). However, in the present study, we did not include single omission of characters into any category, following the practice by Shen and Bear (2000). As suggested by Shen and Bear (2000), blanks provide no information as to the child's knowledge (whether phonological, orthographic, or semantic) of the character, and thus further analysis of this type of spelling error is not possible. The total number of single omission of characters was $2,160,514$, and 657 at Time 1, Time 2, and Time 3, respectively in the present study. Among all 251 children's spelling samples, $51(20.32 \%)$ were independently coded by two well-trained research assistants, and their interrater reliability was $89 \%(K=0.89$, 


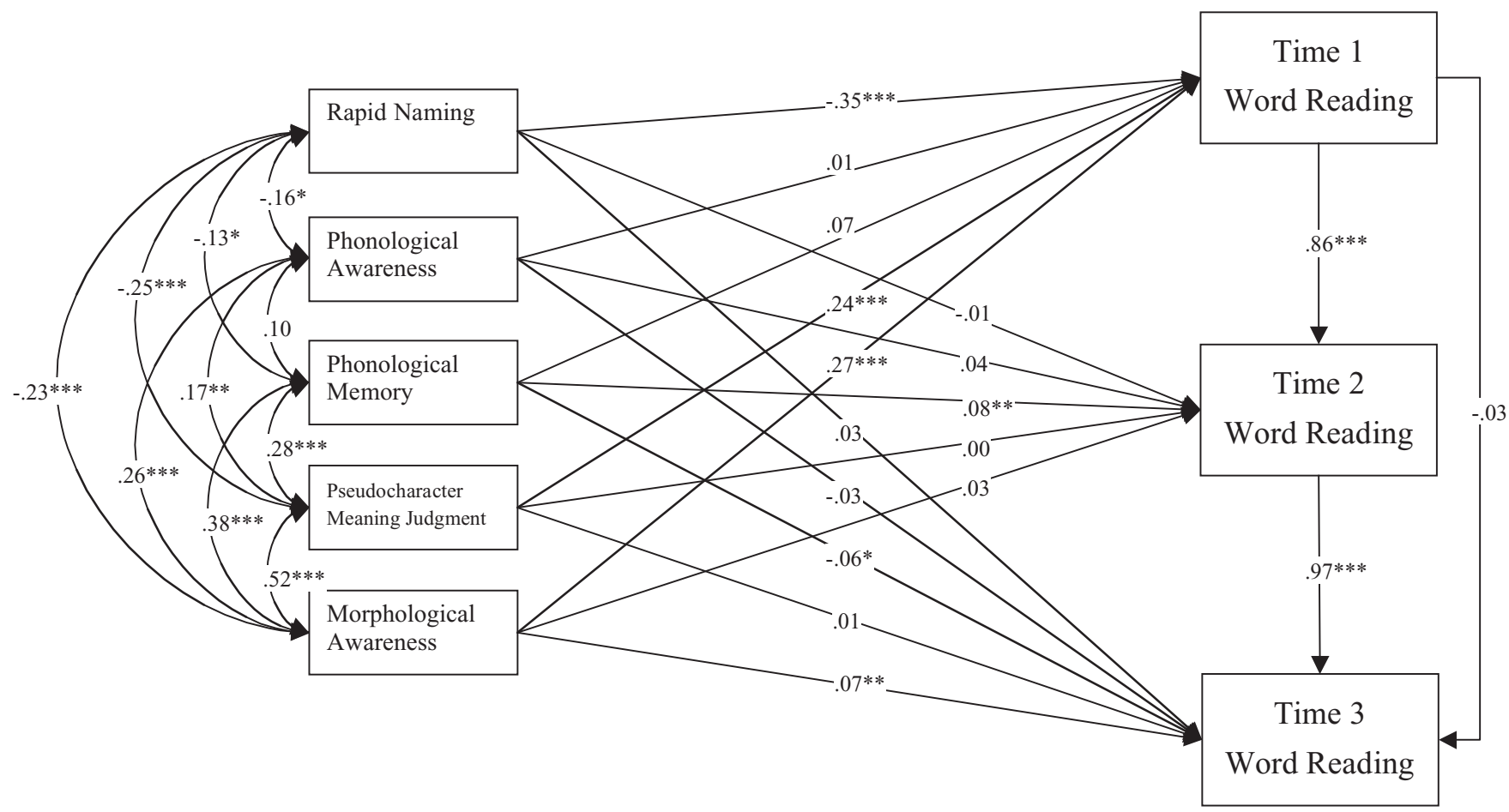

Figure 1. Path diagram of longitudinal predictors of Chinese word reading. Morphological awareness refers to the average $z$ score of homophone awareness and morphological construction. ${ }^{*} p<.05 . * * p<.01 . * * * p<.001$. 


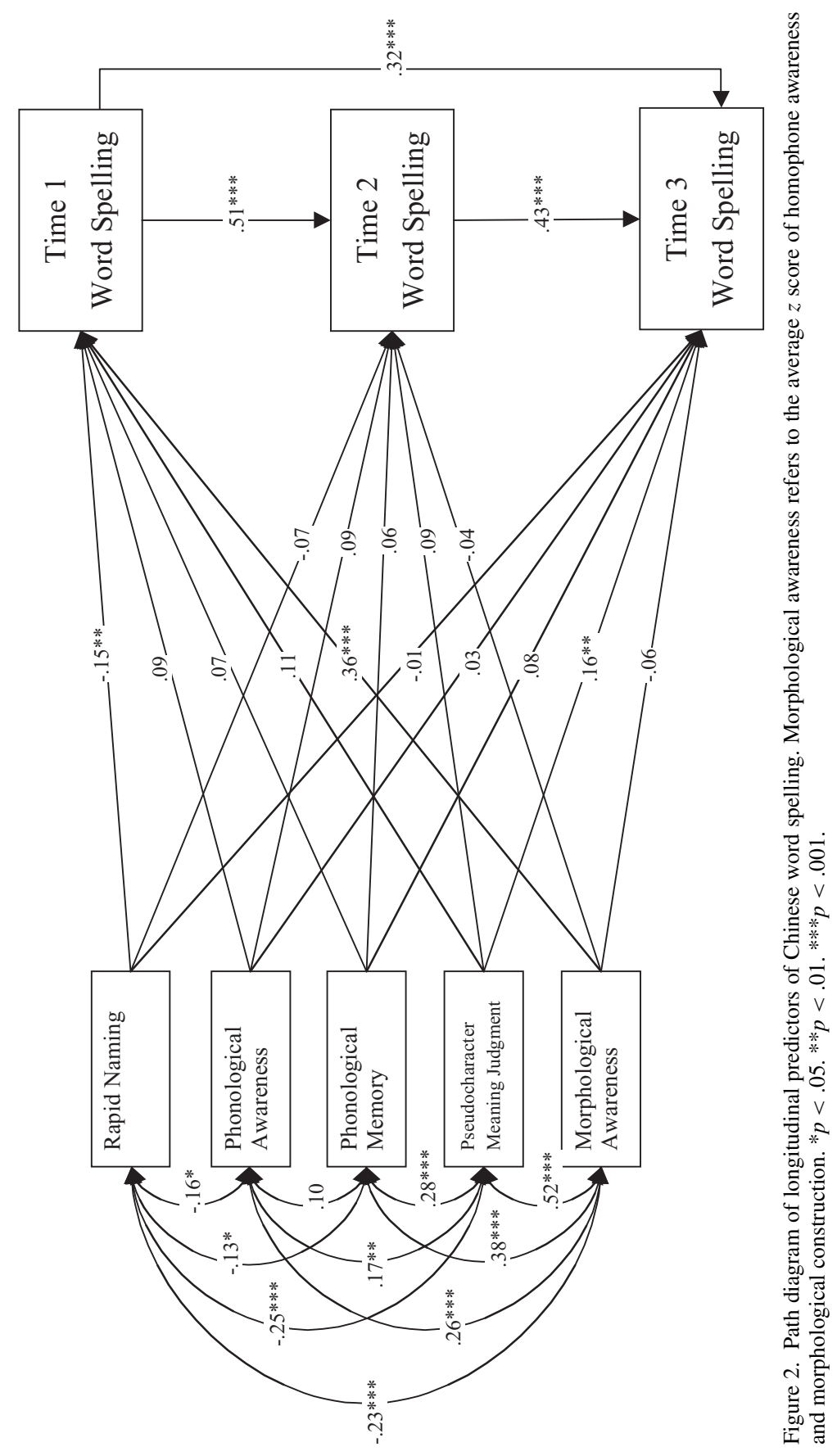


$p<.001)$. The distribution of the different types of errors across the three general categories at Time 1, Time 2, and Time 3 is shown in Table 6.

Detailed analyses of the three categories of spelling errors were adopted from the study by Shen and Bear (2000). One major difference was that the pinyin substitution (i.e., using pinyin to substitute for characters), which accounted for the highest percentage of spelling errors in Grades 1 to 4 in their study, was not included in the present study. Children in Hong Kong were not taught with the assistance of any phonetic system, and this type of spelling error was not found in their responses. There were two types of phonologically based spelling errors: homophonic and similar-sound character substitutions. Children substituted characters that share the same sound (homophone) 想 [soeng2] (think) or a very similar sound (only differ from the target character in onset, rhyme, or tone) 教 [gaau3] (teach) for the target characters 賞 [soeng2] (appreciate) and 夠 [gau3] (enough), respectively. In both cases, the substituted characters were totally different in shape and meaning from the target characters. These phonologically based spelling errors accounted for $15 \%, 3 \%$, and $8 \%$ of Time 1, Time 2, and Time 3 total errors, respectively.

Orthographic-based errors were the most predominant category of errors, accounting for $80 \%, 95 \%$, and $90 \%$ of Time 1, Time 2, and Time 3 total errors, respectively. They include character substitutions similar in sound and shape, single stroke errors, nonphonetic radical substitutions, changes in configuration, partial characters, and substitutions of a shape-similar character. Character substitutions similar in sound and shape refer to the target character being substituted by a character that is similar in both sound and shape; for example, 霜 [soeng1] (frost) is substituted for 箱 [soengl] (box). Single stroke errors refer to those invented spellings with one stroke added to or deleted from the target character or one incorrect stroke; for example, the characters 賽 [tsoi3] (contest) and 光 [gwongl] (light) are misspelled 賽 and 光, respectively. This is the most common type of error across time, occupying 50\%, 71\%, and $65 \%$ at Time 1 , Time 2 , and Time 3 , respectively. Nonphonetic radical substitutions refer to substitutions of graphically similar radicals that have no meaning connections; for example, 永 is substituted for 冰 [bing1] (ice). Changes in configuration refer to using conventional patterns of configuration incorrectly to construct characters; for example, the character 能 [nang4] (able) is misspelled 㫐. Partial characters refer to a character that is represented by part of it or only one radical (but not the phonetic radical); for example, the character 施 [sil] (carry out) is misspelled 方. Substitutions of a shape-similar character refer to the target character being substituted by a character that is similar in shape but not in meaning or sound; for example, 兩 [loeng2] (two) is substituted for 雨 [jy5] (rain).

Semantic spelling errors include invention of an unconventional character, substitution of an irrelevant character, substitution of a shape- and meaning-similar character, and synonym substitution. This category of errors accounted for $5 \%$, $3 \%$, and $2 \%$ of Time 1 , Time 2 , and Time 3 total errors, respectively. Invention of an unconventional character refers to errors that are imaginary characters, showing that the children try to convey the meaning of a target character using the conventional pattern incorrectly; for example, 矔 is substituted for 觀 [gun 1] (view). Substitution of an irrelevant character refers to those invented spellings that are not similar to the target characters in sound, shape, or meaning, but 
Table 6. Distribution by percentage and number of different types of spelling errors and chi-square tests for differences among Time 1, Time 2, and Time 3 for all types of spelling errors in the spelling tests

\begin{tabular}{|c|c|c|c|c|c|}
\hline & & Time 1 & Time 2 & Time 3 & \\
\hline Error Category & Error Type & $\%$ (No.) & $\%$ (No.) & $\%$ (No.) & $\chi^{2}(2, N=251)$ \\
\hline \multirow[t]{3}{*}{ Phonological } & 1. Homophone & $9.1(95)$ & $1.9(25)$ & $4.0(53)$ & $67.09 * * *$ \\
\hline & 2. Similar-sound character substitution & $6.3(66)$ & $0.9(12)$ & $4.0(54)$ & $49.12 * * *$ \\
\hline & Subtotal & $15.5(161)$ & $2.8(37)$ & $8.0(107)$ & $112.79 * * *$ \\
\hline \multirow[t]{7}{*}{ Orthographic } & 3. Character substitution similar in sound and shape & $3.9(41)$ & $4.0(53)$ & $10.6(142)$ & $58.44 * * *$ \\
\hline & 4. Addition or deletion of a stroke/incorrect stroke & $50.3(523)$ & $71.2(935)$ & $64.8(867)$ & $41.42 * * *$ \\
\hline & 5. Nonphonetic radical substitution & $2.0(21)$ & $0.1(1)$ & $0.2(3)$ & $38.71 * * *$ \\
\hline & 6. Change in configuration & $1.2(12)$ & $0.8(10)$ & $1.5(20)$ & 3.13 \\
\hline & 7. Partial character & $14.9(155)$ & $14.6(192)$ & $11.3(151)$ & $7.61 *$ \\
\hline & 8. Substitution of a shape-similar character & $7.7(80)$ & $4.0(52)$ & $1.3(17)$ & $59.81 * * *$ \\
\hline & Subtotal & $80.0(832)$ & $94.7(1243)$ & $89.7(1200)$ & $14.29 * * *$ \\
\hline \multirow[t]{5}{*}{ Semantic } & 9. Invention of an unconventional character & $0.1(1)$ & $0.1(1)$ & $0.0(0)$ & 1.18 \\
\hline & 10. Substitution of an irrelevant character & $3.9(41)$ & $1.7(22)$ & $1.2(16)$ & $22.68 * * *$ \\
\hline & 11. Substitution of a shape- and meaning-similar character & $0.0(0)$ & $0.0(0)$ & $0.1(2)$ & 3.52 \\
\hline & 12. Synonym substitution & $0.5(5)$ & $0.8(10)$ & $1.0(13)$ & 1.86 \\
\hline & Subtotal & $4.5(47)$ & $2.5(33)$ & $2.3(31)$ & $11.09 * * *$ \\
\hline Total & & $100(1040)$ & $100(1313)$ & $100(1338)$ & \\
\hline
\end{tabular}

Note. ${ }^{*} p<.05 . * * * p<.001$. 
involve substitutions based on children's knowledge of Chinese vocabulary; for example, 已 [gei2] (oneself) is substituted for 自 [dzi6] (oneself). Another type of error is the target characters being substituted by a shape- and meaning-similar character; for example, 圍 [wai4] (surround) is substituted for 團 [tyn4] (round). Finally, synonym substitution refers to the target character being substituted by a character similar in meaning; for example, 櫃 [gwai6] (cupboard) is substituted for 箱 [soeng1] (box).

The frequencies of the three main categories of spelling errors including phonologically based errors, orthographic-based errors, and semantic errors were significantly different, $\chi^{2}(2, N=251)=1037.94, p<.001$ at Time $1, \chi^{2}(2, N=251)=$ $2222.81, p<.001$ at Time 2 , and $\chi^{2}(2, N=251)=1918.52, p<.001$ at Time 3 . Further analyses showed that all three types of errors differed from each other at all three periods of assessment $\left(\chi^{2} s>358.47, p s<.001\right)$. It was also found that the relation between time and the three types of errors was significant, $\chi^{2}(4, N=$ $251)=138.17, p<.001$. This suggested that the distribution of spelling error types changes over time.

\section{DISCUSSION}

\section{Important predictors for word reading in Chinese in different grades}

In general, the results of the multiple regression analyses and the path analyses were consistent with our hypotheses regarding the longitudinal predictive power of the reading-related skills on word reading. As expected, rapid naming in Grade 1 was a significant predictor of Chinese word reading in Grade 1 only. It ceased to have a direct effect on word reading in higher grades after controlling for the autoregressor effects. Morphological awareness in Grade 1 was a significant longitudinal predictor of Chinese word reading across time in Grade 1 and Grade 4 after the contributions by the other variables were controlled for in the path analyses. Two findings were not consistent with our hypotheses. First, though multiple regression results showed that orthographic skills in Grade 1 significantly predicted Chinese word reading from Grades 1 to 4, path analyses results suggest that it influenced word reading in higher grades mainly through its contribution on word reading in Grade 1. Second, path analyses showed that phonological memory in Grade 1 was a significant predictor of word reading in Grades 2 and 4, but the direction of relationship was negative in Grade 4.

Consistent with previous findings among Hong Kong children (Tong et al., 2009; Yeung et al., 2011), rapid naming is a strong predictor of Chinese word reading among younger participants. This shows the influence of the characteristics of the Chinese writing system. The smallest orthographic unit of Chinese is relatively coarse, and a less detailed phonological analysis is involved when reading it (Upward, 1999). The rapid naming skill may reflect the ability of learning arbitrary associations required in early grades, whereas it may also reflect the automatic processing of orthographic information and name retrieval required in later learning (Ho, Chan, Tsang, \& Lee, 2002; Ho, Chan, Tsang, Lee, \& Luan, 2004). Together with the fact that the "look and say" method is the instructional method commonly found in Hong Kong classrooms, rapid naming is an important 
predictor of Chinese word reading. The fact that rapid naming in Grade 1 was not a significant longitudinal predictor of subsequent word reading after the autoregressor effects were controlled is consistent with the suggestion that rapid naming's contribution to word reading is taken up by the orthographic skills in higher grades (Roman et al., 2009). To test this hypothesis, findings from future studies with the inclusion of orthographic skills in higher grades are needed.

The significant contribution of orthographic skills, in terms of knowledge related to semantic radicals, to Chinese word reading in Grade 1 was in line with the findings from previous studies (Ho et al., 2003; Yeung et al., 2011). Ho et al. (2003) investigated extensively children's radical knowledge among Grade 1-Grade 5 Chinese children in Hong Kong. They found that children's overall knowledge of the position, function, and semantic category of semantic radicals was associated more strongly with word reading and sentence comprehension than all other tasks assessing radical knowledge. In the context of phonological awareness, rapid naming, and morphological awareness, an orthographic knowledge of semantic radicals significantly predicted Chinese word reading and sentence comprehension among Grade 1 children (Yeung et al., 2011). It is consistent with the general consensus that most Chinese semantic radicals provide a useful cue to the meaning of whole characters (Feldman \& Siok, 1999). The semantic cues offered by the semantic radicals facilitate children's ability to retrieve the sound of the character via the orthography-semantic-phonology pathway. As for the orthographic skills related to the phonetic radical, findings from the present study suggest that its relationship with word reading might not be as strong as other variables. Chen (1993) labeled the script-sound regularity inherent in the phonetic radical in Chinese orthography-phonology correspondence rules. Some researchers considered this as the counterpart of grapheme-phoneme correspondence rules in alphabetic language (Chen, 1993). Shu, Anderson, and Wu (2000) showed that Chinese children as young as second graders are better able to read regular characters than irregular characters. Chen et al. (2004) and Ho et al. (1999) also showed that Chinese kindergartens and first graders were able to use the orthographic analogy strategy to read Chinese characters. As mentioned, semantic radicals are functionally more reliable than phonetic ones. Although using an orthographic analogy strategy is one useful way to infer the sound of Chinese characters, the orthographic knowledge of the phonetic radical might be less important to learning to read Chinese compared to other reading-related skills investigated in the present study. To sum up, results in the present study supported the notion that orthographic skills, including those related to the positions and functions of radicals, have a pervasive influence on learning to read Chinese at a very early age. However, path analyses results suggest that orthographic knowledge in early grades did not have a strong direct effect on subsequent reading. Given the complexity of the Chinese writing system, it takes years to develop the orthographic knowledge in Chinese. This pattern of results might reflect the fact that the orthographic knowledge required to identify the more complex words in higher grades is quite different from those used in Grade 1. This suggestion has to be verified with data from studies incorporating longitudinal measures of orthographic knowledge.

Once again, our findings supported the suggestion that morphological awareness is essential to Chinese word reading development and its influence was 
evident across children of different ages (McBride-Chang et al., 2003, 2005; Shu et al., 2006; Tong et al., 2009; Yeung et al., 2011). This may be because Chinese characters represent morphemes more directly than do the graphemic units of other writing systems (Packard, 2002). Given the presence of a large number of homophones, the ability to discriminate the meanings across homophones is important for children to establish an accurate sound-meaning mapping which in turn facilitates the mapping of meaning from printed words. At the same time, children who are aware of the fact that the same pronunciation can have distinct meanings may be more sensitive to the morphological or contextual clues that may help distinguish meaning, which surely helps their lexical development (Li, Anderson, Nagy, \& Zhang, 2002). With a clear compounding morphological structure, a knowledge of morphemes allows children to have an educated guess when they encounter unfamiliar words in isolation or in a passage (McBride-Chang et al., 2003; Shu et al., 2006). In the context of the autoregressor effects and other variables, morphological construction was the only measure that longitudinally predicted word reading in Grade 4. Results from the present study supported the strong predictive power of morphological awareness in Chinese word reading across time.

One unexpected finding was that phonological memory was a significant predictor of word reading in Grade 2 but was negatively related to word reading in Grade 4. Compared to phonological memory, phonological awareness was more commonly used as a phonological skills measure in studies on Chinese reading (McBride-Chang et al., 2003, 2005; Tong et al., 2009; Yeung et al., 2011). The study by Chan et al. (2006) was one of the few that showed the significance of phonological memory in Chinese word reading among elementary grade students. One speculation for these intriguing results was that Chinese word reading among young children relies a lot on direct script-sound retrieval as suggested by the importance of rapid naming in early Chinese reading. The quality of their phonological representation, as reflected by their phonological memory, is likely to affect their reading ability in early grades. Besides, with the relatively smaller number of words encountered in lower grades, children can utilize their vocabulary knowledge to guess the pronunication of a two-character word based on the sound of one of the characters. However, as grades advanced, this strategy not only cannot facilitate word reading but may negatively affect their reading accuracy given the prevalence of homophones in Chinese. Instead, morphological awareness, which includes the ability to discriminate among the homophones of different morphemes, becomes more important in word recognition in higher grades. These issues need to be carefully examined in future studies.

\section{Important predictors for word spelling in Chinese in different grades}

Results of the multiple regression analyses and path analyses suggest that the longitudinal significant predictors for Chinese word spelling were not that similar to those for Chinese word reading as originally hypothesized. There have been few studies examining the significant predictors of both Chinese word reading and word spelling across different elementary grades. Previous studies focusing on participants either in lower elementary grades (Tong et al., 2009; Yeung 
Yeung et al.: Predictors of Chinese reading and spelling

et al., 2011) or upper elementary grades (Shu et al., 2006) revealed great similarities between Chinese word reading and spelling in terms of their significant predictors. The findings that longitudinal predictors of Chinese word reading and spelling differ over time in the present study reiterated the need for more research efforts on Chinese word spelling development on its own right. The major similarity between Chinese word reading and spelling lies in the results for Grade 1, where rapid naming and morphological awareness were significant predictors of both Chinese word reading and spelling. As expected, both path analyses and spelling errors analyses suggest that phonological skills are not as important as other reading-related skills in Chinese spelling development. However, path analyses showed that the only significant longitudinal predictor of Chinese word spelling in the context of autoregressor effects was orthographic skills involving the knowledge of the semantic radicals, not morphological awareness as found in Chinese word reading.

Similar to word reading, results regarding the significance of rapid naming in word spelling over time were consistent with our hypothesis. Rapid naming was a significant predictor of Grade 1 spelling. After controlling for the autoregressor effects, orthographic skills, but not rapid naming, was a significant longitudinal predictor of spelling. This was in line with the suggestion that rapid naming contributes to orthographic skills development, and its importance in reading and spelling is taken up by orthographic skills in advanced grades (Roman et al., 2009). There are two possible reasons behind the predictive power of rapid naming on word spelling. First, Chinese classroom instruction on writing relies heavily on rote memorization. Teachers typically demonstrate how to write the character stroke by stroke on the blackboard and the children copy characters until they internalized their production as a motor skill (Packard et al., 2006). Second, the learning of the visual form of the simple characters that made up $26 \%$ of the Chinese characters in the primary school curriculum in Hong Kong (Chung \& Leung, 2008), the 200-odd semantic radicals and around 800 phonetic radicals (Hoosain, 1991), also depends a lot on rote memory. Because rapid naming is closely associated with the ability to form arbitrary relationships between visual symbol and sound, it is expected to be closely related to learning to spell Chinese characters.

Consistent with our hypothesis, phonological skills only played a limited role in Chinese spelling. Though phonological awareness and phonological memory were significant predictors of Chinese word spelling at Time 2 and Time 3, respectively, they ceased to be significant predictors of Chinese word spelling in the context of autoregressor effects according to the path analyses. Spelling errors analyses also showed that phonologically based errors only accounted for 3\%-15\% of the total errors in Grades 1 to 4 . These findings not only differ from those in alphabetic languages but also from studies among Chinese children in mainland China (e.g., Shen \& Bear, 2000). In the study by Shen and Bear (2000), phonological skills played an important role in spelling among early elementary grade students, and around $60 \%$ to $90 \%$ of the spelling errors in Grades 1 to 4 are phonologically based errors. There were two possible reasons to explain the relatively less significant role of phonological skills in Chinese word spelling among participants in the present study. First, "Chinese orthography is one of the most phonologically opaque 
writing systems in the world" (Packard et al., 2006, p. 461). The consistency of the phonetic radicals in representing the phonological information in characters is relatively low compared to alphabetic languages. In other words, the orthographyphonology correspondence rules in Chinese might be less reliable in helping children to arrive at the correct spelling in Chinese. As a result, phonological skills, in terms of phonological awareness and phonological memory, are likely to be less important to learning to write Chinese than in alphabetic orthographies. Second, the findings may reflect differences in reading and writing instructions in mainland China and Hong Kong. In mainland China, children are taught pinyin, a phonetic alphabet that is used to spell the syllables, during the first 10 weeks of first grade. To aid character pronunciation, pinyin is written above all the characters in the first- and second-grade textbooks (Packard et al., 2006). Pinyin substitution is the most common type of spelling error among Grades 1 to 4 students in the study by Shen and Bear (2000). On the other hand, the majority of children in Hong Kong are taught to read and write Chinese without the assistance of any phonetic alphabetic system. Though phonological awareness was a weak but significant predictor of Chinese spelling in the study by Tong et al. (2009) and the present study, phonologically based errors only accounted for around 5\% and $15 \%$ of the total spelling errors among Grade 1 Hong Kong children in their study and the present study, respectively.

One important finding in the present study was the predominant role of orthographic skills in Chinese spelling as compared to other reading-related skills as grades advanced. The pseudocharacter meaning judgment task, a measure of the orthographic skills, was a significant predictor of Chinese word spelling in Grades 2 and 4. Moreover, it was the only significant predictor of Chinese spelling in Grade 4 after controlling for the autoregressor effects. Orthographically based errors were the most common type of spelling errors in Grades 1 to 4 . These were consistent with the findings in Shen and Bear's (2000) study, where children showed an increasing use of orthographic strategy as grades advanced. Other than identifying the morpheme, orthographic skills, including knowledge about the regularities of character structure and the orthosemantic and orthophonological regularities of the radicals, are important to successful retrieval of the written form of the character. Orthographic skills are acquired by repeated exposure to printed words until a stable visual representation of the whole word, or meaningful subword units, has been established (Barker et al., 1992). It takes years for sophisticated orthographic skills to develop, and the orthographic phase is the last phase of reading and spelling development in most models (e.g., Frith, 1980). Besides, the items in the spelling task were made up of words that are of difficulty appropriate for each grade. The stimuli words in the Grade 4 spelling task were of lower frequency compared to those in Grades 1 and 2. Orthographic regularities were particularly influential in the naming of low frequency words (Hue, 1992; Lee, Tsai, Su, Tzeng, \& Hung, 2005). It is possible that orthographic skills about the regularities inherent in the Chinese writing system became increasingly important as the children encountered more low frequency words in higher grades.

As for morphological awareness, its importance among younger participants is understandable from the fact that about $60 \%$ of Chinese characters have homophones and almost a quarter of them have six or more homophones (Hoosain, 
1991). In the study by Tong et al. (2009), morpholexically based errors were the most dominant type of spelling errors, accounting for $73 \%-92 \%$ of the total errors, among Hong Kong kindergartners. Though the importance of morphological strategy in Tong et al. (2009) might have been inflated by the fact that omission of a single character was classified as a kind of morpholexically based errors, their findings suggest that morphological awareness does play a significant role in Chinese word spelling even among young children. Although morphological awareness was not a significant longitudinal predictor of Chinese word spelling beyond Grade 1 in the present study, it cannot be concluded that morphological awareness is not important to Chinese word spelling in advanced grades. As noted by Li et al. (2002), one special feature of the Chinese writing system is that it serves to differentiate morphemes that are homophones in the spoken language. Apart from a few exceptions, each morpheme is written with its own unique character. In spelling Chinese characters, one must first be able to identify the particular morpheme of that character among the homophones having the same sound before retrieving the particular orthographic form associated with that morpheme. Therefore, the ability to differentiate the different morphemes having the same pronunciation is most basic to spelling Chinese characters. If children fail to differentiate among the homophones correctly, they will commit the phonologically based spelling error of homophone and possibly the orthographic-based error of character substitution similar in sound and shape. In other words, even when children are using a phonological strategy or an orthographic strategy in Chinese character spelling, their spelling performance is affected by their morphological awareness. Considering the importance of morphological awareness in Chinese word spelling, we not only have to pay attention to the semantic errors category (accounted for $4.5 \%, 2.5 \%$, and 2.3\% of total errors at Time 1, Time 2, and Time 3 , respectively) but also the error types of homophone (accounted for $9.1 \%, 1.9 \%$, and $4.0 \%$ of total errors at Time 1 , Time 2 , and Time 3 , respectively) and character substitution similar in sound and shape (accounted for 3.9\%, 4.0\%, and $10.6 \%$ of total errors at Time 1, Time 2, and Time 3, respectively). Together these three types of errors accounted for $17.5 \%, 8.4 \%$, and $16.9 \%$ of total spelling errors at Time 1, Time 2, and Time 3, respectively. This suggests that morphological awareness does have an influence on word spelling across time. There is more evidence of the importance of morphological awareness in Chinese word spelling. The orthographic knowledge about the location and function of the semantic radicals measured in the pseudocharacter meaning judgment task is closely related to children's semantic information acquisition (Packard et al., 2006). It was suggested that the semantic radicals resemble many of the characteristics of the construct of "morpheme" because most of them signify a particular meaning (Taft, Liu, \& Zhu, 1998). In this way, the fact that the pseudocharacter meaning judgment task was the only significant longitudinal predictor of Chinese spelling does not contradict our hypothesis that children make more use of semantic information as grades advance. It only suggests that semantic information in the subcharacter level is important to learning to spell Chinese words in advanced grades whereas semantic information at the character/word level, as assessed by the morphological awareness tasks, is more adeptly utilized in Chinese spelling among younger children. Because of the script-sound-meaning convergence in Chinese characters, 
morphological knowledge and orthographic knowledge are particularly intertwined in Chinese orthography; for example, the understanding of the role of semantic radicals was conceptualized as a kind of morphological awareness (apart from morpheme awareness and homograph awareness) in the study by Li et al. (2002). Yet the radical has been shown to be an important orthographic processing unit in the study by Ho et al. (2003) and radical awareness is claimed to be directly related to orthographic processing (Wang, Cheng, \& Chen, 2006). Findings in the present study reiterated the need to reconceptualize the constructs of "morphological knowledge" and "orthographic knowledge" in Chinese characters if we are to advance our understanding of Chinese reading and spelling development.

\section{Conclusion}

The present study addressed the paucity of data on the longitudinal predictive power of the four main types of reading-related skills (rapid naming, phonological skills, orthographic skills, and morphological awareness) to Chinese word reading and spelling among elementary grade students. One interesting finding was that the skills important to learning to read Chinese and those for learning to spell Chinese across time differ in significant ways. Although both rapid naming and morphological awareness in Grade 1 were significant predictors of concurrent Chinese word reading and spelling performance, Chinese word reading in Grade 4 was significantly predicted by morphological awareness, and Chinese word spelling in Grade 4 was significantly predicted by orthographic skills after controlling for autoregressor effects. Findings in the present study call for more research efforts on understanding Chinese spelling development, a relatively less explored domain, and reconceptualization of the constructs of "morphological knowledge" and "orthographic knowledge" in Chinese. The results that children's Grade 1 reading-related skills significantly predicted their reading and spelling performance reaffirmed the importance of early intervention.

\section{Limitations and future directions}

There are two major limitations in this study. First, the amount of variance in word spelling explained by the four types of reading-related skills was not so substantial. This may be due to the fact that the range of scores in the word spelling task was relatively limited. It might also suggest some factors important to learning to spell Chinese were yet to be investigated. There were at least two possible candidates, visual-motor integration skills (Berninger, 2004) and stroke order (Lo et al., 2010). Second, the present study only examined word reading and spelling development from Grade 1 to early Grade 4. In the literature on alphabetic language reading and spelling development, strategy specialization between spelling and reading are transitory in nature. The various skills involved become better integrated as reading and spelling ability advances (Bryant \& Bradley, 1980; Lennox \& Siegel, 1993, 1996). Data covering longer periods of development are necessary for verifying these suggestions. 
Yeung et al.: Predictors of Chinese reading and spelling

\section{ACKNOWLEDGMENTS}

This research was funded by the READ \& WRITE: A Jockey Club Learning Support Network from The Hong Kong Jockey Club Charities Trust. Special thanks are due to Ms. Suk-han Lee, University of Hong Kong, and Ms. Suk-man Tsang, Education Bureau, Hong Kong Special Administrative Region Government, Hong Kong, for their valuable advice and suggestions. The authors thank the teachers and students of the two participating schools for their support.

\section{REFERENCES}

Aaron, P. G., \& Joshi, R. M. (1992). Reading problems: Consultation and remediation. New York: Guilford Press.

Adams, M. J. (1990). Beginning to read: Thinking and learning about print. Cambridge, MA: MIT Press.

Barker, T. A., Torgesen, J. K., \& Wagner, R. K. (1992). The role of orthographic processing skills on five different reading tasks. Reading Research Quarterly, 27, 335-345.

Berninger, V. (2004). Understanding the graphia in dysgraphia. In D. Dewey \& D. Tupper (Eds.), Developmental motor disorders: A neuropsychological perspective. New York: Guilford Press.

Bowers, P. G., \& Swanson, L. B. (1991). Naming speed deficits in reading disability: Multiple measures of a singular process. Journal of Experimental Child Psychology, 51, 195-219.

Bowey, J. A., McGuigan, M., \& Ruschena, A. (2005). On the association between serial naming speed for letters and digits and word-reading skill: Towards a developmental account. Journal of Research in Reading, 28, 400-422.

Bradley, L., \& Bryant, P. E. (1983). Categorizing sounds and learning to read-a causal connection. Nature, 301, 419-421.

Bradley, L. L., \& Bryant, P. E. (1985). Rhyme and reason in reading and spelling. Ann Arbor, MI: University of Michigan Press.

Brown, G. D. A., \& Ellis, N. C. (Eds.). (1994). Handbook of spelling: Theory, process, and application. Chichester: Wiley.

Bryant, P. E., \& Bradley, L. (1980). Why children sometimes write words which they do not read. In U. Frith (Ed.), Cognitive processes in spelling. London: Academic Press.

Bryant, P. E., \& Bradley, L. (1983). Psychological strategies and the development of reading and writing. In M. Martlew (Ed.), The psychology of written language. Chichester: Wiley.

Carlisle, J. F. (1995). Morphological awareness and early reading achievement. In L. B. Feldman (Ed.), Morphological aspects of language processing (pp. 189-209). Hillsdale, NJ: Erlbaum.

Castles, A., \& Nation, K. (2006). How does orthographic learning happen? In S. Andrews (Ed.), From inkmarks to ideas: Current issues in lexical processing (pp. 151-179). Hove: Psychology Press.

Chan, D. W., Ho, C. S. H., Tsang, S. M., Lee, S. H., \& Chung, K. K. H. (2006). Exploring the readingwriting connection in Chinese children with dyslexia in Hong Kong. Reading and Writing, 19, 543-561.

Chan, M. Y. (1982). Statistics on the strokes of present-day Chinese script. Chinese Linguistics, 1, 299-305.

Chen, X., Anderson, R. C., Li, W. L., Hao, M. L., Wu, X. C., \& Shu, H. (2004). Phonological awareness of bilingual and monolingual Chinese children. Journal of Educational Psychology, 96, 142-151.

Chen, Y. P. (1993). Word recognition and reading in Chinese. PhD dissertation, Oxford University.

Cheung, K., \& Bauer, R. S. (2002). The representation of Cantonese with Chinese characters. Journal of Chinese Linguistics Monograph Series, 18, 487.

Chung, F. H.-K., \& Leung, M.-T. (2008). Data analysis of Chinese characters in primary school corpora of Hong Kong and mainland China: Preliminary theoretical interpretations. Clinical Linguistics and Phonetics, 22, 379-389.

Cunningham, A. E., \& Stanovich, K. E. (1991). Tracking the unique effects of print exposure in children: Associations with vocabulary, general knowledge, and spelling. Journal of Educational Psychology, 83, 264-274. 
Yeung et al.: Predictors of Chinese reading and spelling

Denckla, M. B., \& Rudel, R. (1976). Rapid "automatized" naming (R. A. N.): Dyslexia differentiated from other learning disabilities. Neuropsychologia, 14, 471-479.

Ehri, L. C. (1992). Reconceptualizing the development of sight word reading and its relationship to recoding. In P. Gough, L. Ehri, \& R. Treiman (Eds.), Reading acquisition (pp. 107-143). Hillsdale, NJ: Erlbaum.

Ehri, L., \& Wilce, L. (1985). Movement into reading: Is the first stage of printed word learning visual or phonetic? Reading Research Quarterly, 20, 163-179.

Fan, K. Y. (1986, September). Graphic symbol of Chinese character modernization. Paper presented at the Symposium of Chinese Character Modernization, Beijing.

Feldman, L. B., \& Siok, W. W. T. (1999). Semantic radicals in phonetic compounds: Implications for visual character recognition in Chinese. In J. Wang, A. W., Inhoff, \& H.-C. Chen (Eds.), Reading Chinese script: A cognitive analysis (pp. 19-35). Mahwah, NJ: Erlbaum.

Frith, U. (1980). Unexpected spelling problems. In U. Frith (Ed.), Cognitive processes in spelling (pp. 495-515). Toronto: Academic Press.

Frith, U. (1985). Beneath the surface of developmental dyslexia. In K. E. Patterson, J. C. Marshall, \& M. Coltheart (Eds.), Surface dyslexia (pp. 301-330). London: Routledge \& Kegan Paul.

Gathercole, S. E., \& Baddeley, A. D. (1989). Evaluation of the role of phonological STM in the development of vocabulary in children: A longitudinal study. Journal of Memory and Language, 28, 200-213.

Gathercole, S. E., Willis, C., \& Baddeley, A. D. (1991). Differentiating phonological memory and awareness of rhyme: Reading and vocabulary development in children. British Journal of Psychology, 82, 387-406.

Gathercole, S. E., Willis, C., Emslie, H., \& Baddeley, A. (1992). Phonological memory and vocabulary development during the early school years: A longitudinal study. Development Psychology, 28, 887-898.

Gentry, J. R. (1982). An analysis of developmental spelling in GNYS at WRK. Reading Teacher, 36, 192-200.

Goswami, U., \& Bryant, P. (1990). Phonological skills and learning to read. Hillsdale, NJ: Erlbaum.

Gough, P. B., \& Hillinger, M. L. (1980). Learning to read: An unnatural act. Bulletin of the Orton Society, 30, 179-196.

Ho, C. S.-H., \& Bryant, P. (1997a). Learning to read Chinese beyond the logographic phase. Reading Research Quarterly, 32, 276-289.

Ho, C. S.-H., \& Bryant, P. (1997b). Phonological skills are important in learning to read Chinese. Developmental Psychology, 33, 946-951.

Ho, C. S.-H., Chan, D. W., Chung, K. K. H., Lee, S.-H., \& Tsang, S.-M. (2007). In search of subtypes of Chinese developmental dyslexia. Journal of Experimental Child Psychology, 97, 61-83.

Ho, C. S.-H., Chan, D. W.-O., Tsang, S.-M., \& Lee, S.-H. (2000). The Hong Kong Test of Specific Learning Difficulties in Reading and Writing. Hong Kong: Hong Kong Specific Learning Difficulties Research Team.

Ho, C. S.-H., Chan, D. W.-O., Tsang, S.-M., \& Lee, S.-H. (2002). The cognitive profile and multipledeficit hypothesis in Chinese developmental dyslexia. Developmental Psychology, 38, 543553.

Ho, C. S.-H., Chan, D. W.-O., Tsang, S.-M., Lee, S.-H., \& Luan, V. H. (2004). Cognitive profiling and preliminary subtyping in Chinese developmental dyslexia. Cognition, 91, 43-75.

Ho, C. S.-H., Ng, T. T., \& Ng, W.-K. (2003). A "radical" approach to reading development in Chinese: The role of semantic radicals and phonetic radicals. Journal of Literacy Research, 35, 849878.

Ho, C. S.-H., Wong, W.-L., \& Chan, W.-S. (1999). The use of orthographic analogies in learning to read Chinese. Journal of Child Psychology and Psychiatry, 40, 393-403.

Hoosain, R. (1991). Psycholinguistic implications for linguistic relativity: A case study of Chinese. Hillsdale, NJ: Erlbaum.

Hue, C. W. (1992). Recognition processes in character naming. In H. C. Chen \& O. J. L. Tzeng (Eds.), Language processing in Chinese (pp. 93-107). Amsterdam: Elsevier Science.

Joshi, R. M., \& Aaron, P. G. (2003). A new way of assessing spelling ability and its classroom implications. In R. M. Joshi, C. K. Leong, \& B. L. J. Kaczmarek (Eds.), Literacy acquisition: The role of phonology, morphology and orthography (pp. 153-161). Washington, DC: IOS Press. 
Yeung et al.: Predictors of Chinese reading and spelling

Kang, J. S. (1993). Analysis of semantics of semantic-phonetics compound characters in modern Chinese. In Y. Chen (Ed.), Information analysis of usage of characters in modern Chinese (pp. 66-83). Shanghai: Shanghai Education.

Kavale, K. A., \& Forness, S. R. (2000). Auditory and visual perception processes and reading ability: A quantitative reanalysis and historical reinterpretation. Learning Disability Quarterly, 23, 253-270.

Kwong, T. E., \& Varnhagen, C. K. (2005). Strategy development and learning to spell new words: Generalization of a process. Developmental Psychology, 41, 148-159.

Lee, C. Y., Tsai, J. L., Su, E. C., Tzeng, O. J. L., \& Hung, D. L. (2005). Consistency, regularity, and frequency effects in naming Chinese characters. Language and Linguistics, 6, 75 -107.

Lee, H. M. (Ed.). (2000). 常用字字形表 [Commonly used Chinese character set]. Hong Kong: Hong Kong Institute of Education.

Lennox, C., \& Siegel, L. S. (1993). Visual and phonological spelling errors in subtypes of children with learning disabilities. Applied Psycholinguistics, 14, 473-488.

Lennox, C., \& Siegel, L. S. (1994). The role of phonological and orthographic processes in learning to spell. In G. D. A. Brown \& N. C. Ellis (Eds.), Handbook of spelling: Theory, process and intervention (pp. 93-109). Chichester: Wiley.

Lennox, C., \& Siegel, L. S. (1996). The development of phonological rules and visual strategies in average and poor spellers. Journal of Experimental Child Psychology, 62, 60-83.

Leung, M. T., \& Lee, A. W. Y. (2002). The Hong Kong corpus of primary school Chinese. Paper presented at the 9 th Meeting of the International Clinical Phonetics and Linguistics Association, Hong Kong.

Li, W., Anderson, R. C., Nagy, W., \& Zhang, H. (2002). Facets of metalinguistic awareness that contribute to Chinese literacy. In W. Li, J. Gaffney, \& J. Packard (Eds.), Chinese children's reading acquisition: Theoretical and pedagogical issues. London: Kluwer Academic.

Lo, L. Y., Yeung, P. S., Ho, C. S. H., Wong, Y. K., Chan, D. W., \& Chung, K. K. H. (2010). The role of stroke knowledge in reading and spelling Chinese. Unpublished manuscript.

Manis, F. R., Doi, L. M., \& Bhadha, B. (2000). Naming speed, phonological awareness, and orthographic knowledge in second graders. Journal of Learning Disabilities, 33, 325-333.

Marsh, G., Friedman, M., Welch, U., \& Desberg, P. (1980). The development of strategies in spelling. In U. Frith (Ed.), Cognitive processes in spelling (pp. 339-353). London: Academic Press.

Mason, J. (1980). When do children begin to read: An exploration of 4-year-old children's letter and word-reading competencies. Reading Research Quarterly, 15, 203-227.

McBride-Chang, C., \& Ho, C. S.-H. (2005). Predictors of beginning reading in Chinese and English: A 2-year longitudinal study of Chinese kindergartners. Scientific Studies of Reading, 9, 117-144.

McBride-Chang, C., Shu, H., Zhou, A., Wat, C. P., \& Wagner, R. K. (2003). Morphological awareness uniquely predicts young children's Chinese character recognition. Journal of Educational Psychology, 95, 743-751.

McBride-Chang, C., Wagner, R. K., Muse, A., Chow, B. W. Y., \& Shu, H. (2005). The role of morphological awareness in children's vocabulary acquisition in English. Applied Psycholinguistics, 26, 415-435.

Moats, L. C. (1995). Spelling: Development, disability, and instruction. Timonium, MD: York Press.

Packard, J. L. (2002). Metalinguistic awareness as a critical construct. In W. Li, J. S. Gaffney, \& J. L. Packard (Eds.), Chinese children's reading acquisition: Theoretical and pedagogical issues (pp. 107-111). Amsterdam: Kluwer.

Packard, J. L., Chen, X., Li, W., Wu, X., Gaffney, J. S., Li, H., et al. (2006). Explicit instruction in orthographic structure and word morphology helps Chinese children learn to write characters. Reading and Writing, 19, 457-487.

Perfetti, C.A., Rieben, L., \& Fayol, M. (Eds.). (1997). Learning to spell: Research, theory and practice across languages. Mahwah, NJ: Erlbaum.

Perfetti, C. A., \& Tan, L. H. (1998). The time course of graphic, phonological, and semantic activation in Chinese character identification. Journal of Experimental Psychology: Learning, Memory, and Cognition, 24, 101-118.

Raven, J. C. (1958). Standard Progressive Matrices. San Antonio, TX: Psychological Corp.

Rego, L. L. B., \& Bryant, P. E. (1993). The connection between phonological, syntactic and semantic skills and children's reading and spelling. European Journal of Psychology of Education, 8, 235-246. 
Yeung et al.: Predictors of Chinese reading and spelling

Rittle-Johnson, B., \& Siegler, R. S. (1999). Learning to spell: Variability, choice, and change in children's strategy use. Child Development, 70, 332-348.

Roman, A. A., Kirby, J. R., Parrila, R. K., Wade-Woolley, L., \& Deacon, S. H. (2009). Toward a comprehensive view of the skills involved in word reading in Grades 4, 6 and 8. Journal of Experimental Child Psychology, 102, 96-113.

Shen, H. H., \& Bear, D. R. (2000). Development of orthographic skills in Chinese children. Reading and Writing, 13, 197-236.

Shu, H., Anderson, R. C., \& Wu, N. (2000). Phonetic awareness: Knowledge of orthography-phonology relationships in the character acquisition of Chinese children. Journal of Educational Psychology, 92, 56-62.

Shu, H., Chen, X., Anderson, R. C., Wu, N., \& Xuan, Y. (2003). Properties of school Chinese: Implications for learning to read. Child Development, 74, 27-47.

Shu, H., McBride-Chang, C., Wu, S., \& Liu, H. (2006). Understanding Chinese developmental dyslexia: Morphological awareness as a core cognitive construct. Journal of Educational Psychology, 98, 122-133.

Siegler, R. S. (1995). How does change occur: A microgenetic study of number conservation. Cognitive Psychology, 28, 225-273.

Snowling, M. J. (1994). Towards a model of spelling acquisition: The development of some component skills. In G. D. A. Brown \& N. C. Ellis (Eds.), Handbook of spelling: Theory, process and intervention (pp. 111-128). Chichester: Wiley.

Sterling, C. M., \& Robson, C. (Eds.). (1992). Psychology, spelling and education. Clevedon: Multilingual Matters.

Taft, M., Liu, Y., \& Zhu, X. (1999). Morphemic processing in reading Chinese. In J. Wang, A. Inhoff, \& H. C. Chen (Eds.), Reading Chinese script: A cognitive analysis (pp. 91-113). Hillsdale, NJ: Erlbaum.

Tong, X., McBride-Chang, C., Shu, H., \& Wong, A. M.-Y. (2009). Morphological awareness, orthographic knowledge, and spelling errors: Keys to understanding early Chinese literacy acquisition. Scientific Studies of Reading, 13, 426-452.

Tunmer, W. E., \& Chapman, J. W. (1998). Implicit and explicit processes in reading acquisition. In K. Kirsner, C. Speelman, M. Maybery, A. O’Brien-Malone, M. Anderson, \& C. MacLeod (Eds.), Implicit and explicit mental processes (pp. 357-370). Mahwah, NJ: Erlbaum.

Upward, C. (1999). Anglo (-Japanese Non-) Dyslexia. Journal of the Simplified Spelling Society, 26, 30-31.

Varnhagen, C. K., McCallum, M., \& Burstow, M. (1997). Is children's spelling naturally stage-like? Reading and Writing, 9, 451-481.

Wagner, R. K., \& Torgesen, J. K. (1987). The nature of phonological processing and its causal role in the acquisition of reading skills. Psychological Bulletin, 101, 192-212.

Wagner, R. K., Torgesen, J. K., Rashotte, C. A., Hecht, S. A., Barker, T. A., Burgess, S. R., et al. (1997). Changing relations between phonological processing abilities and word-level reading as children develop from beginning to skilled readers: A 5-year longitudinal study. Developmental Psychology, 33, 468-479.

Wang, M., Cheng, C. X., Chen, S. W. (2006). Contribution of morphological awareness to ChineseEnglish biliteracy acquisition. Journal of Educational Psychology, 98, 542-553.

Yeung, P. S., Ho, C. S. H., Chik, P. P. M., Lo, L. Y., Luan, H., Chan, D. W. O., et al. (2011). Reading and spelling Chinese among beginning readers: What skills make a difference? Scientific Studies of Reading, 15, 285-313.

Yin, L., Anderson, R. C., \& Zhu, J. (2007). Stages in Chinese children's reading of English words. Journal of Educational Psychology, 99, 852-866.

Zhou, Y. K. (1980). Precise guide to pronunciation with Chinese phonological roots [in Chinese]. Jilin, China: People's Publishing.

Zhu, Y. P. (1987). Analysis of cuing functions of the phonetic in modern China [in Chinese]. Shanghai: East China Normal University-Shanghai. 